\title{
Acute Myocarditis Related to COVID-19: Comparison to SARS and MERS
}

\author{
Angeliki M. Chasouraki ${ }^{1}$ (D) Odyssefs A. Violetis ${ }^{1} \cdot$ Mahmoud Abdelrasoul $^{1} \cdot$ Eleftheria P. Tsagalou $^{2}$
}

Accepted: 29 September 2020 / Published online: 20 November 2020

(C) Springer Nature Switzerland AG 2020

\begin{abstract}
Myocardial involvement has been described during previous SARS and MERS outbreaks. Infection by SARS-CoV-2 (COVID19) can range from asymptomatic to life-threatening multi-system disease. Heart involvement most commonly occurs during severe COVID-19 infection. Myocardial injury, based on elevated levels of myocardial enzymes, has been noted in up to $30 \%$ of patients with COVID-19 infection and could be a marker for worse prognosis. A few cases of possible myocarditis due to SARS$\mathrm{CoV}-2$ have been described, providing variable degree of evidence of direct myocardial involvement. We reviewed in detail those cases in comparison to relevant literature on SARS and MERS and attempted to draw initial conclusions in regard to clinical presentation, treatment and prognosis.
\end{abstract}

Keywords COVID-19 $\cdot$ Myocarditis $\cdot$ Myocardial injury $\cdot$ Troponin $\cdot$ Corticosteroids $\cdot$ Treatment

\section{Introduction}

Infection by the new coronavirus SARS-CoV-2 (COVID-19 infection) is a multi-systemic illness [1]. Cardiac injury has been reported in $20 \%$ to $30 \%$ of hospitalised patients [2]. Reported cardiac involvement includes arrhythmias, acute myocardial infarction, heart failure and cardiogenic shock [2], (https://www.escardio.org/Education/COVID-19-andCardiology/ESC-COVID-19-Guidance).

This article is part of the Topical Collection on COVID-19

Angeliki M. Chasouraki

angchasouraki@gmail.com

Odyssefs A. Violetis

odysseas.violetis@gmail.com

Mahmoud Abdelrasoul

mahmabdel@gmail.com

Eleftheria P. Tsagalou

tsagalou@gmail.com

1 Internal Medicine Clinic, Pammakaristos Hospital of Divine Providence (Reference Centre for COVID-19 infection), Iakovaton 43, 11144 Athens, Greece

2 Therapeutic Clinic, Alexandra University Hospital, Lourou 4-2, 11528 Athens, Greece
Acute myocarditis is another condition which has been reported to complicate the COVID-19 infection [3]. Ten cases have been reported so far. Cases of acute myocarditis have been previously attributed to other coronaviruses such as SARS-CoV and MERS-CoV [4, 5]. In fact, postmortem real-time polymerase chain reaction analyses of heart tissue from the SARS epidemic, detected the viral genome in $35 \%$ of patients $(n=7 / 20)$ who died from SARS (https://www. escardio.org/Education/COVID-19-and-Cardiology/ESCCOVID-19-Guidance). SARS-COV-2 mRNA has also been detected in autopsy specimens as well as endomyocardial biopsies in patients with suspected myocarditis. [6,7]

\section{Pathogenesis of Myocardial Injury}

Increases in troponin I and CK-MB, which are suggestive of myocardial injury, are frequent findings in COVID 19 disease and associated with adverse prognosis. Huang et al. reported that $31 \%$ of patients with COVID-19 hospitalised in ICU had an increase in troponin I compared to $4 \%$ of non-ICU patients [8]. In a meta-analysis, including 341 patients, levels of troponin I were significantly increased in critically ill patients as opposed to those with milder illness [9]. Suggested mechanisms of myocardial injury during COVID-19 infection are the following: 
1. Direct injury through connection to ACE2 receptors that are expressed in the myocardium.

2. Indirect injury due to the systemic inflammatory response syndrome (SIRS) and the cytokine storm that the infection provokes [10].

3. Infection-induced vasculitis attributed either to contamination of the endothelial cells or to immunological response [3].

Binding to ACE2 receptors is the entrance point of SARSCoV-2. These receptors are expressed, among others, in the epithelial cells of lungs, heart and enterocytes [10,11]. These same receptors were also found to be the entrance point of SARS-CoV. Both viruses seem to be able to modulate the ACE2 myocardial and pulmonary pathways, leading to inflammation of the heart, pulmonary oedema and acute respiratory failure [12]. Myocardial inflammation in SARS-CoV infection can also be mediated by macrophages entering the myocardial tissue and producing cytokines [4].

\section{Clinical Presentation-Symptoms and Signs}

Acute myocarditis may present with chest pain, fever, dyspnoea, signs of heart failure and ECG abnormalities like STinterval or T-wave changes. [13]

SARS-CoV-2 We reviewed ten published case reports of infection by SARS-CoV-2, presenting as acute myocarditis [14-23]. The cases included 6 male and 3 female patients, aged between 17 and 69 years. In one case, a 17 year old male, eosinophilic myocarditis was diagnosed postmortem after experiencing out of hospital cardiac arrest. Five of the patients presented with chest pain $[14,15,19,21,23]$. Dyspnoea was another main symptom reported in 6 cases [15, 16, 18, 21-23]. More details regarding their clinical presentation are presented in Table 1.

MERS-CoV We found a single case report involving a MERS$\mathrm{CoV}$ infection complicated with acute myocarditis. The case involved a 60 -year-old man who presented with pneumonia and congestive heart failure. Main symptoms were fever, dyspnoea, cough with sputum and left-sided chest pain. On clinical examination he had widespread crackles and elevated jugular venous pressure [5].

\section{Laboratory Findings}

SARS-CoV-2 All reported cases (except the case which included the 17-year-old patient) presented with increased levels of troponin ranging from 590 to $11.000 \mathrm{ng} / \mathrm{L}$ [14-23]. Four of them had elevated NT-pro-BNP levels that ranged between
1300 and $8465 \mathrm{pg} / \mathrm{ml}$ [16-19] and two had elevated NTBNP levels which peak accounted for $22.600 \mathrm{pg} / \mathrm{ml}[15$, 21]. Other markers suggestive of myocardial injury that were found elevated in certain patients were myoglobin and CKMB [15, 17, 21]. Detailed information on laboratory findings is available in Table 2 .

Regarding the full blood count leukocytosis and lymphocytopenia were noticeable in four patients. These findings are common among COVID-19 patients and can predict the severity of the infection [24].

Patients with COVID-19 and acute myocarditis were also found to have increased levels of IL-6, IL- $1 \beta$ and IL-10 [15, $17,25]$. The virus is known to induce production of IL- 6 and IL-1, among other cytokines, through at least 2 distinct pathways, as recently described [26].

Electrocardiogram was available in all 9 patients. STsegment elevation was evident in 3 cases $[17,19,21]$ and Twave inversion in 2 cases $[17,22]$ while the rest had nonspecific findings such as sinus tachycardia, intraventricular conduction delay or non-specific repolarization abnormalities.

Echocardiography revealed a wide range of findings. Seven out of nine patients had moderate to severe left ventricular dysfunction (left ventricular ejection fraction ranging between 25 and 40\%) [15, 17, 19, 21, 23]. Other findings included increased wall thickness, hypokinesia and pericardial effusion [15, 17-19, 21, 23].

Definite diagnosis with cardiovascular magnetic resonance was available in six cases. Myocardial oedema and late gadolinium enhancement demonstrated in all cases $[14,16-18,22$, 23]. More information regarding investigations is available in Table 3.

SARS-CoV SARS-CoV infection can also be complicated with acute myocarditis as indicated by SARS-CoV genome detected in the heart tissue [3]. A 30-day follow-up study measured cardiac output in patients infected by SARS-CoV during hospitalisation and at follow-up. Measurements were significantly lower during hospitalisation. Infection-induced myocarditis may lead to myocardial dysfunction [27].

MERS-CoV Acute myocarditis can also be one of the manifestations caused by MERS-CoV. A case presented with increased troponin I and pro-BNP levels. ECG showed diffuse T-wave inversions and echocardiography revealed severe left ventricular systolic dysfunction. MRI findings were in accordance with clinical suspicion revealing myocardial oedema and late gadolinium enhancement (LGE) [5].

\section{Pathologic Findings}

The 17-year old patient who had the postmortem diagnosis of COVID-19 had undergone autopsy. The microscopic 

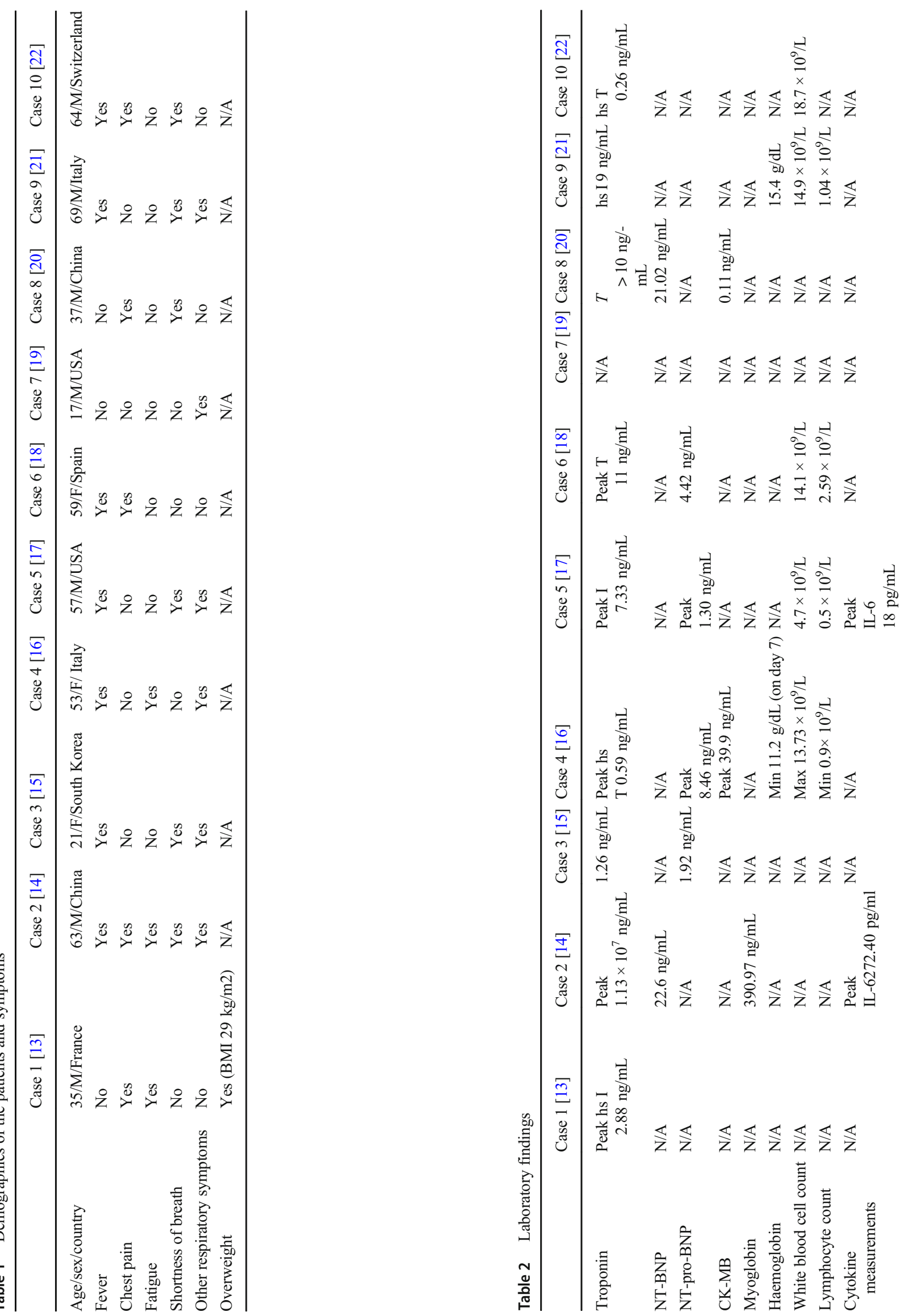


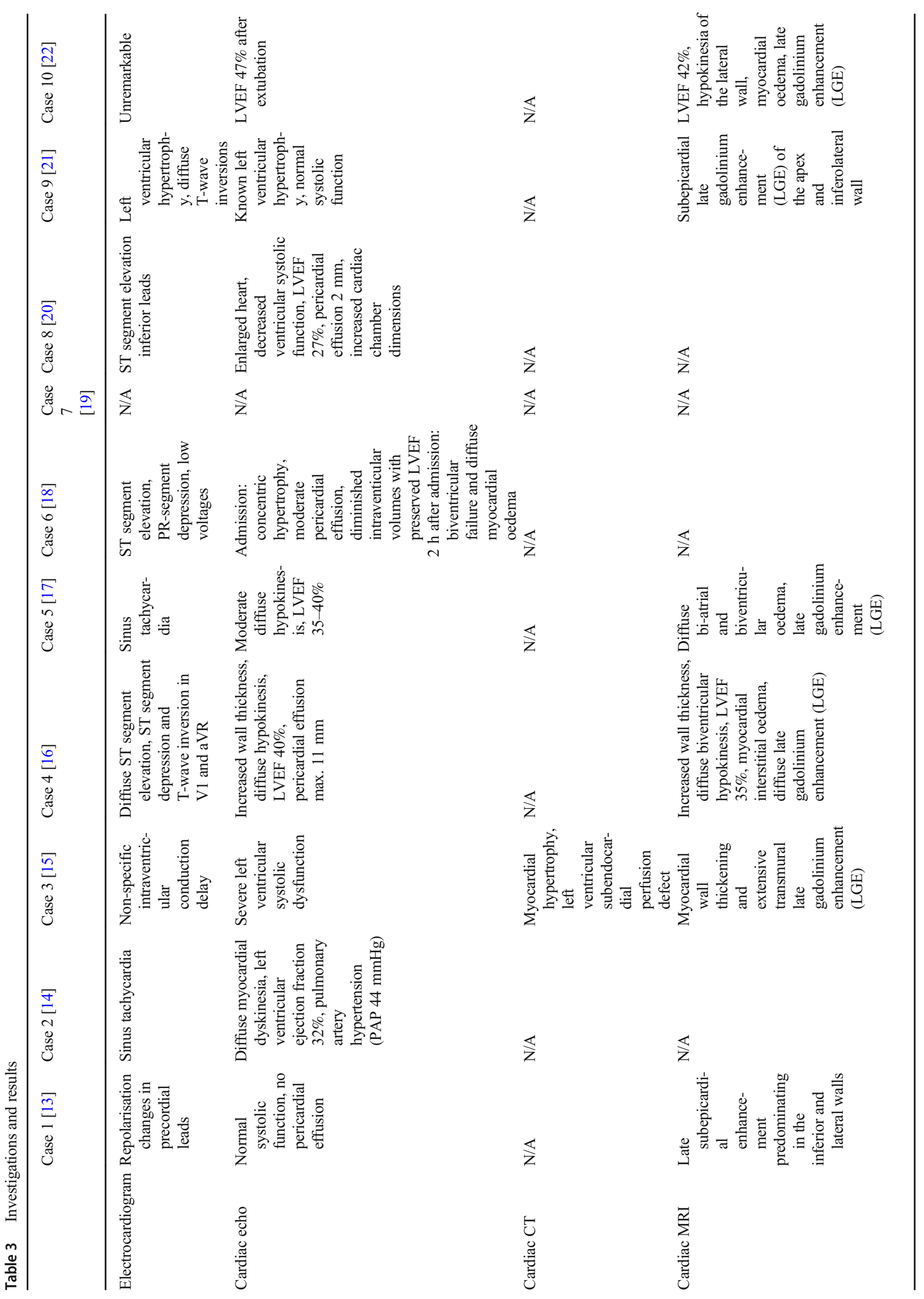




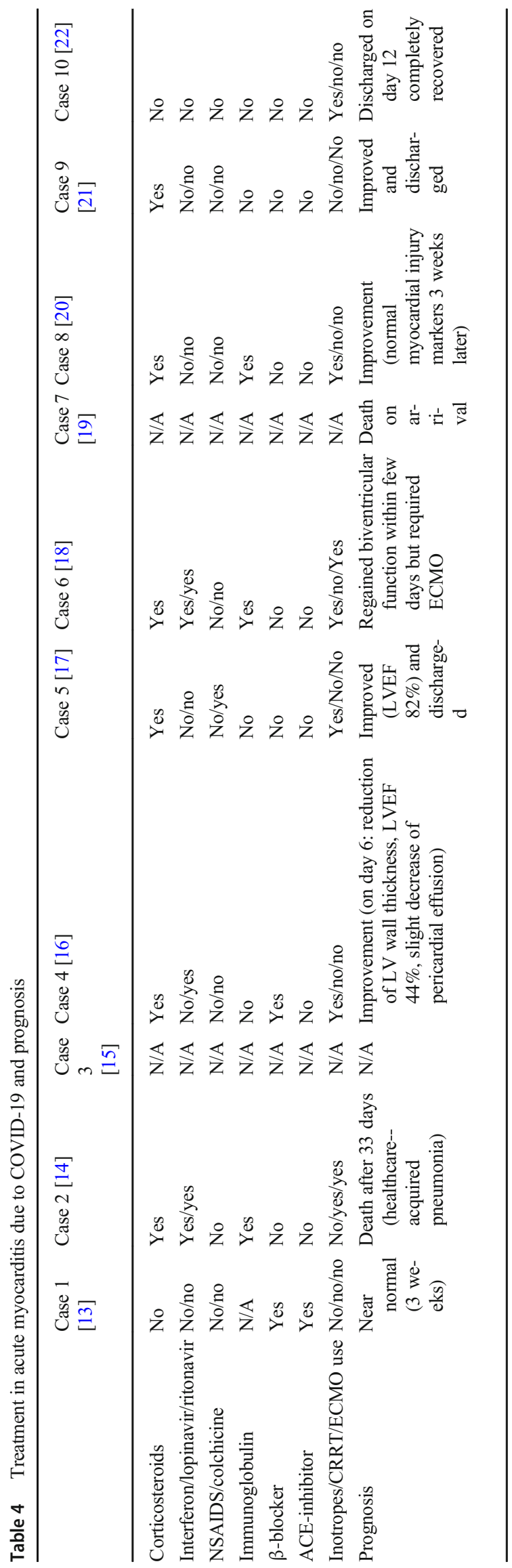

examination of the heart revealed biventricular necrosis and infiltration of inflammatory cells, mostly eosinophils [20]. Sporadic in other cases cardiac biopsies have revealed lymphocytes and other inflammatory cells residing in the myocardium [28].

\section{Treatment}

SARS-CoV-2 Almost all patients received corticosteroids as part of their treatment [15, 17-19, 21, 22]. IV methylprednisolone was the drug of choice. Corticosteroids (namely dexamethasone) are included in a recently proposed therapeutic algorithm from Athens, Greece [29] and have been shown to offer a survival advantage in severe COVID-19 infection according to a recent announcement by the RECOVERY investigators (https://www.recoverytrial.net/news/low-costdexamethasone-reduces-death-by-up-to-one-third-inhospitalised-patients-with-severe-respiratory-complicationsof-covid-19). Immunoglobulin [15, 19, 21] and anti-viral therapy were administered to less than half of the patients. Antiviral therapy included lopinavir/ritonavir (400 mg/100 mg) and was administered twice daily $[15,17,19]$. Additionally, two out of seven patients required ECMO during their hospitalisation $[15,19]$. A detailed course of treatment of each case is presented in Table 4.

MERS-CoV The only reported case presenting with acute myocarditis received broad-spectrum antibiotics and IV furosemide [5].

\section{Prognosis}

SARS-CoV-2 Among the aforementioned cases with COVID19 two died, the 17-year-old patient who experienced out of hospital cardiac arrest and a patient who recovered from fulminant myocarditis only to die at the 33rd day of his hospitalization due to secondary infection $[14,20]$. The rest of the patients improved within several days (6-20 days). Their troponin levels dropped $[14,21]$, the LVEF improved $[17,18$, 23] and myocardial wall thickness was restored [17].

SARS-CoV Patients with SARS-COV infection and traceable genome of the virus in their heart tissue had poorer prognosis compared to those with non-traceable virus. The latter's shorter hospitalisation period ( 7 days vs. 13 days) indicates that cardiac involvement may lead to severe illness and earlier death [4].

MERS-CoV The only registered case with MERS-COV infection complicated with acute myocarditis showed no 
improvement in left ventricular systolic function 3 months after being discharged [5].

\section{Conclusions}

Previous experience with SARS-CoV and current reports of COVID-19 infection mandate a high level of clinical suspicion for cardiovascular involvement, myocardial injury and possibly acute myocarditis. Diagnosis of acute myocarditis as a result of COVID-19 may be challenging for clinicians. High levels of troponin I and NT-BNP along with ECG abnormalities and the appropriate clinical context should raise suspicion. Cardiac magnetic resonance has proven to be a useful diagnostic tool in acute myocarditis cases. So far, most patients have favourable outcomes but the limited data cannot allow us to draw safe conclusions.

\section{Compliance with Ethical Standards}

Conflict of Interest The authors declare that they have no conflict of interest.

\section{References}

1. Spuntarelli V, Luciani M, Bentivegna E, Marini V, Falangone F, Conforti G, et al. COVID-19: is it just a lung disease? A case-based review. SN Compr Clin Med. 2020. https://doi.org/10.1007/ s42399-020-00418-6.

2. Shi S, Qin M, Shen B, et al. Association of cardiac injury with mortality in hospitalized patients with COVID-19 in Wuhan, China. JAMA Cardiol. 2020. https://doi.org/10.1001/jamacardio. 2020.0950

3. Atri D, Siddiqi H, Lang J, et al. COVID-19 for the cardiologist: a current review of the virology, Clinical Epidemiology, Cardiac and Other Clinical Manifestations and Potential Therapeutic Strategies. JACC: Basic Transl Sci. 2020. https://doi.org/10.1016/j.jacbts. 2020.04.002.

4. Oudit GY, Kassiri Z, Jiang C, Liu PP, Poutanen SM, Penninger JM, et al. SARS-coronavirus modulation of myocardial ACE2 expression and inflammation in patients with SARS. Eur J Clin Investig. 2009;39(7):618-25. https://doi.org/10.1111/j.1365-2362.2009. 02153.x.

5. Alhogbani T. Acute myocarditis associated with novel Middle East respiratory syndrome coronavirus. Ann Saudi Med. 2016;36(1). https://doi.org/10.5144/0256-4947.2016.78.

6. Wichmann D, Sperhake JP, Lutgehetmann M, et al. Autopsy findings and venous thromboembolism in patients withcovid-19: a prospective cohort study. Ann Intern Med. 2020. https://doi.org/10. 7326/M20-2003.

7. Wenzel P, Kopp S, Göbel S, Jansen T, Geyer M, Hahn F, et al. Evidence of SARS-CoV-2 mRNA in endomyocardial biopsies of patients with clinically suspected myocarditis tested negative for COVID-19 in nasopharyngeal swab. Cardiovasc Res. 2020. https://doi.org/10.1093/cvr/cvaa160.

8. Huang $\mathrm{C}$, Wang $\mathrm{Y}$, Xingwang $\mathrm{L}$, et al. Clinical features of patients infected with 2019 novel coronavirus in Wuhan, China. Lancet. 2020;395(10223):497-506. https://doi.org/10.1016/S01406736(20)30183-5.
9. Lippi G, Lavie CJ, Sanchis-Gomar F. Cardiac troponin I in patients with coronavirus disease 2019 (COVID-19): evidence from a metaanalysis. Progress in cardiovascular diseases, S00330620(20)30055-4. Advance online publication. 2020. https://doi. org/10.1016/j.pcad.2020.03.001.

10. Bansal M. Cardiovascular disease and COVID-19. Diabetes Metab Syndr. 2020;14(3):247-50. https://doi.org/10.1016/j.dsx.2020.03. 013.

11. Long B, Brady WJ, Koyfman A, Gottlieb M. Cardiovascular complications in COVID-19. Am J Emerg Med, Advance online publication. 2020. https://doi.org/10.1016/j.ajem.2020.04.048.

12. Xiong T, Redwood S, Prendergast B, Chen M. Coronaviruses and the cardiovascular system: acute and long-term implications. Eur Heart J. 2020. https://doi.org/10.1093/eurheartj/ehaa231.

13. Blauwet LA, Cooper LT. Myocarditis. Prog Cardiovasc Dis. 2010;52(4):274-88. https://doi.org/10.1016/j.pcad.2009.11.006.

14. Paul J-F, Charles P, Richaud C, Caussin C, Diakov C. Myocarditis revealing COVID-19 infection in a young patient. Eur Heart J Cardiovasc Imaging. 2020;21:776. https://doi.org/10.1093/ehjci/ jeaa107.

15. Zeng J, Liu Y, Yuan J, et al. First case of COVID-19 complicated with fulminant myocarditis: a case report and insights. Infection. 2020. https://doi.org/10.1007/s15010-020-01424-5.

16. Kim I-C, Kim JY, Kim HA, Han S. COVID-19-related myocarditis in a 21-year-old female patient. Eur Heart J. 2020. https://doi.org/ 10.1093/eurheartj/ehaa288.

17. Inciardi RM, Lupi L, Zaccone $\mathrm{G}$, et al. Cardiac involvement in a patient with coronavirus disease 2019 (COVID-19). JAMA Cardiol. 2020. https://doi.org/10.1001/jamacardio.2020.1096.

18. Coyle J, Igbinomwanhia E, Sanchez-Nadales A, Danciu S, Chu C, Shah N. A recovered case of COVID-19 myocarditis and ARDS treated with corticosteroids, tocilizumab, and experimental AT-001. JACC Case Rep. 2020. https://doi.org/10.1016/j.jaccas.2020.04. 025 .

19. Irabien-Ortiz Á, Carreras-Mora J, Sionis A, Pàmies J, Montiel J, Tauron M. Fulminant myocarditis due to COVID-19. Revista espanola de cardiologia (English ed.), S1885-5857(20)30165-1. 2020. Advance online publication. https://doi.org/10.1016/j.rec. 2020.04.005.

20. Craver R, Huber S, Sandomirsky M, McKenna D, Schieffelin J, Finger L. Fatal eosinophilic myocarditis in a healthy 17-year-old male with severe acute respiratory syndrome coronavirus 2 (SARSCoV-2c). Fetal Pediatr Pathol. 2020;1-6. Advance online publication. https://doi.org/10.1080/15513815.2020.1761491.

21. $\mathrm{Hu} \mathrm{H}, \mathrm{Ma}$ F, Wei X, Fang Y. Coronavirus fulminant myocarditis saved with glucocorticoid and human immunoglobulin. Eur Heart J. 2020; ehaa190. Advance online publication. https://doi.org/10. 1093/eurheartj/ehaa190.

22. Doyen D, Moceri P, Ducreux D, Dellamonica J. Myocarditis in a patient with COVID-19: a cause of raised troponin and ECG changes. Lancet. 2020;395(10235):P1516. https://doi.org/10.1016/ S0140-6736(20)30912-0.

23. Pavon AG, Meier D, Samim D, Rotzinger DC, Fournier S, Marquis $\mathrm{P}$, et al. First documentation of persistent SARS-CoV-2 infection presenting with late acute severe myocarditis. Can J Cardiol. 2020. https://doi.org/10.1016/j.cjca.2020.06.005.

24. Violetis O, Chasouraki A, Giannou A, Baraboutis I. COVID-19 infection and haematological involvement: a review of epidemiology, pathophysiology and prognosis of full blood count findings. SN Compr Clin Med. 2020. https://doi.org/10.1007/s42399-02000380-3.

25. Ma L, Song K, Huang Y. Coronavirus disease 2019(COVID-19) and cardiovascular complications. J Cardiothorac Vasc Anaesth. 2020. https://doi.org/10.1053/j.jvca.2020.04.

26. Giamarellos-Bourboulis EJ, Netea MG, Rovina N, et al. Complex immune dysregulation in COVID-19 patients with severe 
respiratory failure. Clinical and Translational Report. Online Now. Cell Host Microbe Open Access. 2020. https://doi.org/10.1016/j. chom.2020.04.009.

27. Li S S-l, Cheng C-w, Fu C-l, et al. Left ventricular performance in patients with severe acute respiratory syndrome. Circulation. 2003;108:1798-803. https://doi.org/10.1161/01.CIR.0000094737. 21775.32 .

28. Hendren N, Drazner M, Bozkurt B, Cooper L. Description and proposed management of the acute COVID-19 cardiovascular syndrome. 2020. https://doi.org/10.1161/CIRCULATIONAHA. 120.047349 .

29. Baraboutis IG, Gargalianos P, Aggelonidou E, et al. Initial real-life experience from a designated COVID-19 Centre in Athens, Greece: a Proposed Therapeutic Algorithm. SN Compr Clin Med. 2020. https://doi.org/10.1007/s42399-020-00324-x36.

Publisher's Note Springer Nature remains neutral with regard to jurisdictional claims in published maps and institutional affiliations. 